\title{
Urgences
}

\section{Jardin de pierres : octobre}

\section{Jean-Paul Daoust et Mario Savoie}

Numéro 16, mars 1987

D.G. Jones : d'un texte, d'autres

URI : https://id.erudit.org/iderudit/025378ar

DOI : https://doi.org/10.7202/025378ar

Aller au sommaire du numéro

Éditeur(s)

Urgences

ISSN

0226-9554 (imprimé)

1927-3924 (numérique)

Découvrir la revue

Citer ce document

Daoust, J.-P. \& Savoie, M. (1987). Jardin de pierres : octobre. Urgences, (16),

30-31. https://doi.org/10.7202/025378ar d'utilisation que vous pouvez consulter en ligne.

https://apropos.erudit.org/fr/usagers/politique-dutilisation/ 
g) Nous aimerions faire remarquer que nous avons respecté l'orthographe du mot «Wat» tel qu'il était écrit sur le manuscrit qui nous a été remis. Signalons en passant que, s'il est vrai que le mot «Wat» peut s'écrire en français avec un "W» ou un « $V$ », nous n'avons jamais trouvé, dans les dictionnaires dont nous disposions, le nom d' "Angkor Vat» écrit avec un «W» mais toujours avec « $V$ ».

\section{Jean-Paul Daoust/Mario Savoie JARDIN DE PIERRES: OCTOBRE}

Dans la pluie, c'est une ruine

hantée, c'est

un tombeau fleuri

Qui ramasse les couleurs

des feuilles mortes. Pourtant

ses pierres fleurissent

comme un fouillis de livres

où les fantômes continuent de

parler

De plus en plus ma bouche

est pleine de pierres

et les os de mes semblables

ressemblent aux fleurs

N'est-ce qu'un enchevêtrement, un paradis

ou Angkor Vat

ou le centre-ville passé

10:00 P.M.? Ce n'est

ni mort ni vivant

ni humain. Je le longe

dans la pluie sombrement. C'est

la naissance des écrits secrets 
La force du langage n'a rien à voir avec la connaissance intrinsèque de l'autre langue et avec l'étrangeté propre, n'est-ce pas, à tout poème. D'abord le titre: non pas complexe mais difficile, et pourtant il a l'air si simple... Difficulté majeure: comment installer le poème dans son contexte le plus adéquat?

Et comment retransmettre l'atmosphère sonore du poème: ses assonances, ses allitérations et d'autres jeux: par exemple, «tomb» et "tomes", ou "more and more my mouth"; vous remarquerez que nous avons travaillé avec le «p» des pierres, donc nous avons osé passer de la douceur de la bouche qui déguste (ces «m») au produit lui-même (matériau opaque?). Et ne pas perdre l'autonomie du texte cible: garder ce mouvement continu entre la mort et la vie où le poète se situe, là encore nous avons joué avec les «f» («fantômes-fleurs-fouillisfleuri-fleurissent») pour remplacer les "g" ("gathering-are gone go on»), pour rester dans ce jardin troublant.

Et la ponctuation... et la mise en page, etc...

Nous avons voulu que notre traduction reste soumise au texte source tout en essayant une transposition idéale. La grande difficulté: respecter l'esprit qui hante ce beau poème. 